\title{
Erradicação de espécies exóticas invasoras: múltiplas visões da realidade brasileira
}

\section{Eradication of Invasive Exotic Species: Multiple Views of the Brazilian Reality}

\author{
Anderson Eduardo Silva OLIVEIRA* \\ Daniel Gomes PEREIRA**
}

\begin{abstract}
RESUMO
A partir de dados secundários, o estudo analisa o universo formado pelos dados científicos e legais e a opinião pública sobre a erradicação de espécies exóticas invasoras no Brasil. As informações consolidadas indicam que os conflitos e incertezas acadêmicas sobre bioinvasão geram lacunas e divergências entre os instrumentos legais existentes. Em adição, observa-se que a distância entre a geração da informação e o acesso dessa pela população é uma das principais causas da postura aversiva à implantação das ações de erradicação. Constata-se que apesar dos avanços científicos e legais, ainda existe grande necessidade de aprimoramento destes componentes no enfrentamento do problema, assim como a efetiva inclusão da sociedade.
\end{abstract}

Palavras-chave: espécies exóticas; espécies exóticas invasoras; erradicação.

\begin{abstract}
Based on secondary data, this study analyzes the universe constituted by scientific data, legal and public opinion on the eradication of invasive exotic species in Brazil. Consolidated information indicates that conflicts and academic uncertainties on bioinvasion create the existing gap and conflicts among existing legal instruments. Moreover, existing gap between information generation and the access of them to population is one of the main causes hindering implementation of eradication actions. Present situation indicates that although scientific and legal advances, components improvement in facing these problems is still greatly needed, as well as society effective inclusion.
\end{abstract}

Key-words: exotic species; invasive exotic species; eradication.

\footnotetext{
"Biólogo, Doutor em Meio Ambiente pela Universidade do Estado do Rio de Janeiro. Atualmente é Líder de Processo e Coordenador Técnico na Habtec Engenharia Ambiental. Email: aoliveir23@yahoo.com.br.

"* Médico Veterinário, Doutor em Meio Ambiente pela Universidade do Estado do Rio de Janeiro. Atualmente é pós-doutorando na Pós-graduação em Ecologia e Evolução da Universidade do Estado do Rio de Janeiro. Email: danielgomesvet@yahoo.com.br.
} 


\section{Introdução}

A Convenção sobre a Diversidade Biológica (CDB), da qual o Brasil é signatário, estabelece que deve-se prevenir e impedir a entrada de espécies exóticas em novos ambientes, assim como controlar ou erradicar espécies exóticas invasoras que ameacem os ecossistemas, habitats ou espécies (MMA, 2000). É considerada como espécie exótica invasora (EEI) aquela que, uma vez introduzida a partir de outro ambiente, estabelece-se em um novo ecossistema ou habitat fora de sua distribuição natural, tornando-se agente de mudança que ameace, em algum grau, a biodiversidade nativa, os recursos naturais e/ou a saúde humana (UICN, 2000; ZILLER, 2001; MATTHEWS; BRAND, 2005; ZILLER; ZALBA, 2007). A introdução de espécies fora da sua distribuição geográfica natural e as consequências da sua permanência em novo ambiente são cada vez mais estudadas, buscando-se avaliar os possíveis impactos decorrentes da introdução (ex. BERGALLO et al., 2000; MMA, 2000; MORSELLO, 2001; PRIMACK; RODRIGUES, 2001; ZILLER, 2001; AGUIRRE et al., 2002; REASER et al., 2005; ZILLER; ZALBA, 2007).

Diante do reconhecimento mundial dos impactos socioambientais causados por EEI's, diversas instituições vêm compilando e publicando manuais que objetivam a divulgação e a orientação de implementação de medidas de combate a este problema (NUÑEZ; QUINTERO, 2002; NISC, 2003; ORUETA, 2003; ZILLER et al., 2007; PARKES et al., 2008). Muitos desses manuais apresentam linha de ação semelhante, na qual figura a sequência iniciada com a prevenção, seguida pelo estabelecimento de mecanismos de detecção precoce, monitoramento e controle (NISC, 2003; ZILLER et al., 2007). Em alguns casos, a erradicação é considerada como alternativa imediata à detecção, antes que a espécie possa se naturalizar e iniciar a dispersão. Em outros casos, a erradicação é considerada como uma das últimas alternativas no controle de EEI's. A opção de erradicação envolve considerações relativas às dificuldades práticas e orçamentárias, assim como a resistência da opinião pública e a controvérsia científica. No Brasil, algumas das propostas de erradicação tornaram-se polêmicas de grandes proporções, incluindo acaloradas discussões acadêmicas, filosóficas e práticas (CAVALCANTI, 2003; GALETTI; SAZIMA, 2006; DEBERDT; SCHERER, 2007; MARTINS et al., 2007; PEREIRA et al., 2008). Apesar do crescente interesse, é insuficientemente documentada a discussão acerca das ações de controle e erradicação de espécies exóticas invasoras, especialmente no Brasil. Por essa razão, o presente estudo procura contribuir para a discussão sobre a erradicação de EEI's no Brasil, através do confronto de dados científicos, legais e da opinião pública. Como resultado da ampla gama de grupos biológicos representantes de EEI's, existe uma infinidade de métodos passíveis de serem empregados para o combate às mesmas. O presente estudo não pretende listá-los, mas apenas discutir os efeitos de alguns dos métodos empregados para o controle das EEI's no âmbito dos avanços científicos, suas consequências na formação da opinião pública e seu alinhamento com os instrumentos legais aplicáveis.

\section{A legislação federal pertinente}

Observando o conteúdo do artigo $3 .{ }^{\circ}$ da Lei n. ${ }^{\circ} 5.197$, de 3 de janeiro de 1967 (BRASIL, 1967), e do artigo 37 da Lei n. ${ }^{\circ} 9.605$, de 12 de fevereiro de 1998 (BRASIL, 1998), o IBAMA elaborou e publicou a Instrução Normativa (IN) 141, de 19 de dezembro de 2006, que regulamenta o controle e o manejo ambiental da fauna nativa ou exótica nociva ao meio ambiente (IBAMA, 2006). No artigo 2. ${ }^{\circ}$ desta IN, a captura seguida de eliminação, ou eliminação direta de espécimes animais, é apresentada como uma das definições de controle. Deve-se observar, entretanto, que a epígrafe $3 .^{\text {a }}$ do artigo $4 .^{\circ}$ desta IN especifica que a eliminação direta de indivíduos das espécies em questão, ou seja, a erradicação, só deverá ser efetuada quando tiverem sido esgotadas as medidas de manejo ambiental. Nesta análise, torna-se relevante observar ainda que a IN 141/2006 trata exclusivamente da fauna, evidenciando a inobservância de registros de EEI's em quase todos os grupos biológicos existentes (PYSEK et al., 2008).

A erradicação de espécies exóticas foi tratada também no Decreto n. ${ }^{\circ} 4.339$, de 22 de agosto de 2002 (BRASIL, 2002), que instituiu a Política Nacional da Biodiversidade. $\mathrm{O}$ item 2.VIII deste decreto preconiza que o poder público deverá determinar medidas para evitar a degradação ambiental quando existir evidência científica de risco sério e irreversível à diversidade biológica. Nesse caso, considerando os impactos negativos de EEI's, pode-se considerar entre as medidas cabíveis a erradicação da espécie que coloca em risco os demais componentes ambientais. O item 11.1.13 do mesmo decreto cita textualmente a recomendação de erradicação e o controle de EEI's que possam afetar a bio- 
diversidade. Já a Resolução CONAMA n. ${ }^{\circ}$ 369, de 28 de março de 2006, em seu artigo 2..$^{\circ}$, reitera as disposições da Lei n. $^{\circ} 4.771$, de 15 de setembro de 1965 , ao considerar de interesse social a erradicação de espécies exóticas invasoras, quando se mostrar necessária a sua adoção para assegurar a proteção da integridade da vegetação nativa (BRASIL, 1965; CONAMA, 2006).

A Convenção sobre a Diversidade Biológica, regulamentada no Brasil pelo Decreto n. ${ }^{\circ} 2.519$, de 16 de março de 1998, recomenda enfrentar o problema de espécies exóticas invasoras com base no Princípio da Precaução (BRASIL, 1998). De acordo com a convenção, a falta de certeza científica não deve ser usada como justificativa para prorrogar ou deixar de implementar ações de erradicação, contenção ou controle. De forma análoga, a ação rápida para prevenir a introdução, o estabelecimento ou a expansão de uma espécie exótica invasora potencial é recomendada ainda que haja incerteza sobre seus impactos no longo prazo (IUCN, 2000). Registra-se então um potencial conflito entre o conteúdo do Decreto n. ${ }^{\circ}$ 4.339/2002, que recomenda a erradicação somente após a evidência científica de risco sério e irreversível à diversidade biológica, e a Convenção de Diversidade Biológica, que recomenda a adoção da precaução, ainda que haja incerteza científica (BRASIL, 2002). Com base no Princípio da Precaução, as decisões de manejo devem ser realizadas antes mesmo da absoluta certeza científica sobre se tal situação configuraria uma ameaça real ao ambiente, bastando a plausibilidade, fundada nos conhecimentos científicos disponíveis na época. O Princípio da Precaução traz, portanto, uma exigência de cálculo precoce dos potenciais perigos para a saúde ou para a atividade de cada um, quando o essencial ainda não surgiu (GODARD, 2004). Mas, deve-se observar que, em se tratando de elementos biológicos, a resposta a condições semelhantes não necessariamente é idêntica. As populações de uma mesma espécie apresentam respostas diferenciadas a condições ambientais diferentes, muitas vezes com diferenças muito sutis.

Apesar do amparo legal já estabelecido, a erradicação de EEI's ainda encontra muitas dificuldades operacionais, especialmente pelas limitações tecnológicas. Tais limitações foram reconhecidas pelo Decreto $n .^{\circ} 4.339 / 2002$ que, em seu item 13.2.7, apontou a necessidade de apoiar e promover o aperfeiçoamento de ações de prevenção, controle e erradicação de EEI's e de espécies-problema (BRASIL, 2002). As dificuldades operacionais tornam-se maiores em ambientes aquáticos, devido à fluidez do mesmo e às formas de reprodução dos organismos.

Essas dificuldades operacionais são convertidas em elevados custos financeiros. E, apesar do item 2.IX do Decreto n. ${ }^{\circ} 4.339 / 2002$ considerar que a internalização dos custos deve se dar levando em conta o princípio do poluidor pagador $^{1}$ (BRASIL, 2002), registra-se que, até o momento, o poder público e os entes afetados pelos efeitos negativos de EEI's têm arcado com os custos. Em parte, esse fato está relacionado com a dificuldade de se estabelecer uma relação de causa e efeito entre os danos e a presença de EEI's, além de, em alguns casos, não ser possível identificar os vetores ou responsáveis pela introdução da espécie exótica. Essa dificuldade é uma realidade comum em casos de múltiplos vetores operantes na região. Ademais, o período de latência ${ }^{2}$ muitas vezes é longo o suficiente para que não seja possível a identificação do vetor de introdução (MATTHEWS; BRAND, 2005), dificultando a aplicação da legislação.

Apesar de muitas das abordagens sobre EEI's tratarem daquelas que afetam sistemas naturais, deve-se observar que algumas EEI's afetam a saúde humana e outras afetam sistemas produtivos. O enfrentamento nacional dessas espécies fica a cargo do Ministério da Saúde e do Ministério da Agricultura, Pecuária e Abastecimento (MAPA). A legislação brasileira prevê que espécies prejudiciais à saúde humana e aos sistemas produtivos sejam passíveis de controle por órgãos de governo da Saúde, da Agricultura e do Meio Ambiente, sem a necessidade de autorização por parte do IBAMA. Deve-se observar, entretanto, que essas espécies não podem constar em listas oficiais de vulnerabilidade, nem na lista CITES 3 .

Considerando o acima exposto, o Ministério da Saúde e seus órgãos adotaram um sistema em que os mesmos enfrentam essas espécies a partir do estabelecimento de instrumentos normativos específicos para cada uma detectada. Já o MAPA adotou um sistema de registro e notificação de

\footnotetext{
${ }^{1}$ De acordo com o princípio do poluidor pagador, em princípio, o poluidor deverá suportar o custo da poluição, com o devido respeito pelo interesse público e sem distorcer o comércio e os investimentos internacionais (MILARÉ, 2007).

${ }^{2}$ Período de latência é o período necessário para que uma espécie, sob determinadas condições, se adapte ao novo ambiente, passe a reproduzir e a disseminar-se (GROVES, 2006).

${ }^{3}$ CITES - sigla referente à Convention on International Trade in Endangered Species; que é o tratado internacional que proíbe o comércio de espécies ameaçadas de extinção da fauna e da flora.
} 
EEI's ${ }^{4}$, que é atualizado periodicamente, e prevê ações de controle e erradicação dessas espécies. O sistema e a lista mais atualizada foi normatizada pela Instrução Normativa MAPA n. ${ }^{\circ} 41$, de 2 de julho de 2008 (MAPA, 2008).

No contexto da discussão, torna-se relevante pontuar que programas de erradicação de EEI's podem incluir uma ampla diversidade de metodologias, por exemplo, técnicas de caça terrestre e/ou aérea, armadilhas com atrativo alimentar ou sexual, envenenamento em iscas ou corte e retirada direta. Todavia, os programas não devem negligenciar o previsto no artigo 32 da Lei n. ${ }^{\circ}$ 9.605/1998, que trata dos crimes relacionados aos maus-tratos a animais (BRASIL, 1998). Esse tem sido um dos principais pontos de resistência da sociedade às ações de erradicação de espécies de fauna exótica invasora.

$\mathrm{Na}$ legislação brasileira, evidencia-se ainda o emprego de diversos termos e conceitos relacionados à Teoria de Bioinvasões, que é resultado da ausência de consenso científico. Tal fato também pode contribuir para aumento dos riscos em decorrência da imposição de dificuldades de intervenção e enfrentamento do problema.

\section{O conhecimento cientifico e seus dilemas}

O aprimoramento da legislação deve refletir o desenvolvimento científico de um tema e não o contrário. Consultas feitas à Plataforma Lattes $(\mathrm{CNPq})$ e ao sistema Web of Science confirmam a insipiência nacional do tema e a raridade de estudos científicos que efetivamente recomendem ações de controle e erradicação de EEI's no Brasil. Como reflexo do distanciamento entre os diversos atores envolvidos no processo, conforme apontado por Oliveira e Machado (2008), observa-se que uma parcela menor ainda de resultados é convertida em informações e encaminhada adequadamente ao poder público. Como consequência, as poucas recomendações de erradicação circulam exclusivamente no meio acadêmico ou chegam tardiamente aos representantes do poder público envolvidos com as tomadas de decisão.

A título de ilustração, podemos trazer como exemplos os casos de três espécies de corais exóticos invasores na costa do Estado do Rio de Janeiro e o caso do molusco mexilhão-dourado. Com base em dados de amostragens pontuais e de monitoramento na baía da Ilha Grande (PAULA; CREED, 2005; CREED; PAULA, 2007; CREED et al., 2008), o Projeto Coral Sol iniciou seu esforço de erradicação das duas espécies do gênero Tubastraea em 2008, ou seja, quase uma década e meia após o seu primeiro registro no litoral do Estado do Rio de Janeiro (PAULA; CREED, 2005). Neste caso, estabeleceu-se o consórcio de atividades de controle das populações das EEIs, desenvolvimento científico e educação ambiental da população de uma das regiões onde estas espécies se estabeleceram. Releva-se pontuar que as iniciativas de controle e erradicação destas espécies iniciaram-se após notificações sem retorno feitas às autoridades cuja missão deveria ser enfrentar os fatores de degradação ambiental, como os impactos gerados pela presença de EEI's (CREED, com. pess.). Oliveira e Medeiros (2008) recomendaram a erradicação do coral exótico invasor Chromonephthea braziliensis após a avaliação do potencial de dispersão da espécie com o auxílio de vetores locais. Entretanto, até o momento não foi documentada qualquer iniciativa pública ou privada neste sentido. Como os autores alertaram, novos focos da espécie continuam sendo detectados na região (dados não publicados). Já o mexilhão-dourado, Limnoperna fortunei, foi documentado pela primeira vez na América do Sul no final de 1991 (DARRIGRAN; PASTORINO, 1993). Entre os anos de 1994 e 1995 foram feitos alertas sobre o crescimento populacional explosivo e o potencial invasor da espécie. Mas, não foram tomadas medidas de controle enquanto as populações ainda estavam confinadas em área relativamente reduzida. Desde 1998, quase anualmente, surgem novos registros da espécie em uma bacia hidrográfica brasileira diferente. Hoje, todo esforço está direcionado na retirada de indivíduos de populações que crescem em taxas alarmantes, tornando-se uma das maiores pragas biológicas no Brasil (DARRIGRAN; DRAGO, 2000; MANSUR et al., 2004; OLIVEIRA et al., 2006).

Um fato relevante à discussão é que, usualmente, os pesquisadores são os primeiros a detectar a presença destas espécies, mas alguns priorizam seus interesses científicos em detrimento do apontamento da necessidade de enfrentamento do problema frente aos riscos socioambientais. Neste caso, para garantir a manutenção do objeto de pesquisa,

\footnotetext{
${ }^{4}$ O Ministério da Agricultura, Pecuária e Abastecimento, assim como todos os órgãos vinculados ao mesmo, empregam o termo "pragas quarentenárias" como sinônimo para espécies exóticas invasoras.
} 
alguns pesquisadores não recomendam ou não iniciam ações de controle das espécies exóticas, ainda que reconheçam os impactos provocados pela espécie.

Apesar do volume crescente de estudos sobre bioinvasões, ainda existem muitas incertezas (FACON et al., 2005), tornando o tema um dos mais controversos da atualidade. Como saber se uma espécie exótica poderá causar impactos negativos sobre populações nativas ou ecossistemas? Por essa razão, alguns grupos argumentam que a detecção precoce, consorciada com as ações de controle, representa uma postura preventiva (ZILLER et al., 2007). De acordo com essa linha de pensamento, não se pode esperar por provas concretas dos impactos para somente então iniciar as ações de controle. A demora pode fazer com que seja tarde demais para resolver o problema. $\mathrm{O}$ reconhecimento da importância de pequenos, embora crescentes, focos de espécies exóticas potencialmente invasoras é algo que ainda não foi incorporado à cultura brasileira de enfrentamento deste problema, conforme se pode notar a partir dos exemplos apresentados anteriormente. Com poucas exceções, é dada atenção insuficiente ao desenvolvimento de uma estratégia eficaz para controlar a propagação das espécies exóticas. Em adição, a ausência de um sistema amplo de monitoramento da biodiversidade dificulta a rápida detecção dessas espécies.

A discussão sobre o controle e a erradicação de espécies exóticas traz à tona a complexidade dos sistemas ecológicos. Essa complexidade materializa-se pela dificuldade em prever os efeitos de uma intervenção, assim como de estabelecer o limite entre quando iniciar a erradicação é uma medida precoce ou quando adiar torna o controle impossível. Zavaletta et al. (2001) e Rodriguez (2006) ressaltam a importância de ver o processo de erradicação como um todo, com efeitos positivos atrelados ao risco de efeitos negativos. Em um sistema complexo como o ecológico, a retirada de um componente, aqui representado pelas EEI's, pode representar uma fonte de desequilíbrio tão séria quanto a introdução.

O Princípio da Precaução tem sido empregado por ativistas pró-erradicação, que consideram que, dadas as dificuldades em conter EEI's já estabelecidas, deve-se priorizar a rápida resposta a estas populações. Mas, de acordo com Godard (2004), a adoção do Princípio da Precaução remete ao empenho no aprimoramento científico e tecnológico dos mecanismos de avaliação e gestão dos riscos. Considerando o exposto por Zavaletta et al. (2001), o mesmo princípio deveria ser usado como argumento para a cautela, uma vez que este princípio afirma que, na ausência da certeza científica formal, a existência de um risco de dano sério ou irreversível requer a implementação de medidas que possam prevenir este dano. Esse argumento torna-se especialmente legítimo ao lembrarmos que a extinção, ainda que local, é para sempre, e que controlando focos nascentes de espécies exóticas, pode-se também estar fazendo uma leitura extremamente pontual do caso e, com isso, impedindo processos naturais da dinâmica das comunidades, de entrada e saída de espécies. Nesse contexto, é importante destacar ainda que, apesar da ampla discussão sobre os conceitos de espécies exóticas, permanecem algumas incertezas sobre os aspectos temporais do conceito, ou seja, a partir de quando deixamos de considerar uma espécie como exótica ou nova na comunidade (DANSEREAU, 1957; ELTON, 1958; CRAWLEY et al., 1997; LOMOLINO et al., 2006). Ao fazermos tal consideração devemos lembrar os fundamentos de biogeografia - que destacam a importância de fenômenos de invasão biológica, neste caso, por razões naturais, para a manutenção de comunidades e ecossistemas (LOMOLINO et al., 2006). Mas, não podemos negligenciar o fato de que a taxa de introdução vem aumentando expressivamente como resultado das intervenções antrópicas e, consequentemente, tem levado ao alarme hoje estabelecido mundialmente.

Mas, agir sem observar as respostas do ambiente pode levar a maus investimentos de recursos humanos e financeiros. Ademais, independentemente do sucesso das ações de controle ou erradicação, uma intervenção inadequada pode colocar em risco outros componentes ambientais presentes no mesmo espaço físico. Rodriguez (2006), após ampla revisão bibliográfica, apresentou exemplos e argumentos que demonstram a importância de EEI's na manutenção de populações de espécies nativas endêmicas ou ameaçadas de extinção. Neste caso, apesar das espécies introduzidas serem capazes de causar alguns impactos ambientais negativos, elas também poderiam facilitar e garantir a viabilidade de outras populações nativas a partir de processos como a modificação de habitat perturbado antropicamente, criação de novos habitats, enriquecimento nutricional do ambiente, diversificação de recursos alimentares e polinização. A chave da questão está em organizar a estratégia de manejo de forma a enfrentar o problema e simultaneamente aumentar o conhecimento científico sobre o tema (RODRIGUEZ, 2006; ZALBA; ZILLER, 2007).

No contexto do manejo preventivo de espécies exóticas invasoras, uma linha crescente considera que a erradicação só pode acontecer antes do término da fase de 
estabelecimento e naturalização da espécie, ou seja, antes da espécie iniciar a sua dispersão e ser efetivamente constatada como espécie exótica invasora (SAKAI et al., 2001; ALLENDORF; LUNDQUIST, 2003). A partir daí, seria aplicável somente o controle do tamanho da população. Simberloff (2003) argumenta que o conhecimento integral da biologia de população das espécies invasoras não é necessário, em algumas circunstâncias, para o manejo e controle. Essa colocação vem sendo entendida como "atire primeiro, faça as perguntas depois”. Essa recomendação está de acordo com algumas experiências com ecologia de populações. A melhor maneira de reduzir a probabilidade de que uma espécie exótica se torne invasora é eliminá-la antes que tenha tempo para se tornar representativa na comunidade invadida e que tenha capacidade de dispersar-se ou desenvolver adaptações que a permitam substituir as espécies nativas (ALLENDORF; LUNDQUIST, 2003). Todavia, não podemos negligenciar o fato de que a entrada de uma nova espécie é algo inerente à dinâmica das comunidades. Além disso, todas as espécies, após a introdução em um novo ambiente, tornam-se igualmente invasoras. O aumento da compreensão da biologia, da genética e dos mecanismos de evolução das populações pode ser muito útil na distinção das espécies introduzidas que são mais propensas a tornarem-se invasoras.

\section{A opinião pública}

Além das questões já apontadas, a opinião pública deve ser considerada como um dos pontos a ser incorporado ao processo de enfrentamento das EEI's e seus impactos. Nesse contexto, deve-se observar que as EEI's são representadas por quase todos os grupos de organismos (PYSEK et al., 2008); entretanto, somente a fauna de vertebrados e as espécies vegetais de interesse etnobotânico são objetos de atenção e carisma público, o que torna estes grupos motivadores de resistência às ações de erradicação.

Muitos ecólogos e produtores rurais precisam de poucos argumentos para convencê-los dos danos e riscos gerados por muitas das espécies exóticas. Entretanto, uma parte considerável do público brasileiro desconhece o problema. No esforço de angariar mais adeptos para o enfrentamento da situação, alguns cientistas e jornalistas tornam-se demasiado enfáticos, tornando o problema mais fantasioso do que realista. Como resultado, um volume considerável de informações equivocadas é propagado, ampliando o desentendimento (LODGE; SHRADER-FRACHETTE, 2003).

Grupos de defesa dos direitos dos animais baseiam-se no artigo 32 da Lei n. ${ }^{\circ}$ 9.605, de 12 de fevereiro de 1998 (BRASIL, 1998), sob a argumentação de que é crime ambiental maltratar animais para posicionar-se contra as ações de controle e erradicação de EEI's. No entanto, na maioria dos casos, negligenciam os efeitos nocivos destas espécies às nativas, o que é considerado no artigo 37 da mesma lei. Essa situação pode ser ilustrada pelo posicionamento do grupo de defesa dos direitos dos animais no caso dos javalis, no Estado do Paraná (GNIPPER; JACOBS, 2009). Mas, este não é um posicionamento exclusivo de grupos ativistas de direitos dos animais brasileiros, conforme se pode constatar no estudo realizado por Soulé (1990). É compreensível o posicionamento destes grupos, especialmente se considerarmos os conflitos científicos, culturais, éticos e legais que envolvem a eliminação de organismos vivos.

$\mathrm{O}$ outro extremo pode ocorrer quando a sociedade adota uma espécie como inimiga, mas a sua semelhança com uma nativa coloca em risco esta última. $\mathrm{O}$ caso pode ser ilustrado pelo molusco Achatina fulica, também conhecido como caramujo-gigante-africano, que vem sendo combatido em todo o Brasil. Sua semelhança com espécies nativas tem sido considerada uma das razões para a coleta equivocada e consequente agravamento dos impactos sobre as espécies nativas, por exemplo, a espécie Megalobulimus sp. (MINISTÉRIO DA SAÚDE - MS, 2007; SIMIÃO; FISCHER, 2004).

O paradoxo das situações descritas ilustra o distanciamento entre a geração e a difusão da informação científica no Brasil. Simultaneamente, evidencia-se a necessidade de incorporação da educação ambiental e adequada comunicação à sociedade sobre o que são espécies exóticas invasoras e quais são os seus riscos ao ambiente e à sociedade. A difusão das razões e das técnicas de manejo das EEI's pode evitar que denúncias de controle destas sejam julgadas pela sociedade como crime ambiental, quando em verdade são ferramentas para a conservação da diversidade biológica. A adequada divulgação do tema e o envolvimento dos mais diversos segmentos da sociedade podem ajudar no estabelecimento de jurisprudência e regulamentação para o tema, tais como listas oficiais de EEI's para referência pública, regulamentação para uso de espécies de valor comercial e análises de risco (ZILLER; ZALBA, 2007). 


\section{Considerações finais}

Diversas ações de conservação da biodiversidade precisam ser realizadas com urgência, muitas vezes, demandando intervenções com informações insuficientes. Algumas dessas ações não podem esperar até que se tenha o conhecimento completo de todos os fatores que operam em cada situação. Esse fato confronta-se com a formação científica tradicional que impulsiona os profissionais, especialmente das ciências naturais, a exaurirem as possibilidades antes da tomada de decisões ou recomendação de intervenções. Por outro lado, não é realista pensar que estudos científicos genéricos possam ser aplicados indiscriminadamente para a tomada de decisão. No cenário atual de degradação ambiental, as decisões precisam ser tomadas geralmente em caráter de urgência. Abster-se de executar uma ação de manejo é uma decisão cujas consequências podem ser tão ou mais graves do que fazer algo de forma equivocada. O manejo

\section{Referências}

AGUIRRE, A. A., OSTFELD, R. S.; TABOR, G. M.; HOUSE, C.; PEARL, M. C. Conservation medicine: ecological health in practice. New York: Oxford University Press, 2002.

ALLENDORF, F. W.; LUNDQUIST, L. L. Introduction: population biology, evolution, and control of invasive species. Conservation Biology, v. 17, p. 24-30, 2003.

BERGALlO, H. G.; GEISE, L.; BONVICINO, C. R.; CERQUEIRA, R.; D'ANDREA, P. S.; ESBERARD, C. E.; FERNANDEZ, F. A. S.; GRELLE, C. E.; PERACCHI, A.; SOICILIANO, S.; VAZ, S. M. Mamíferos. In: BERGALLO, H. G.; ROCHA, C. F. D.; ALVES, M. A. S.; VAN SLUYS, M. (Eds.). A fauna ameaçada de extinção do Estado do Rio de Janeiro. Rio de Janeiro: EdUERJ, 2000.

BRASIL. Lei n. 4.771, de 15 de setembro de 1965. Institui o novo Código Florestal. Brasília: DOU de 16/9/1965.

Lei n. 5.197, de 3 de janeiro de 1967. Dispõe sobre a proteção à fauna e dá outras providências. Brasília: DOU de $5 / 1 / 1967$.

. Lei n. 9.605, de 12 de fevereiro de 1998. Dispõe sobre as sanções penais e administrativas derivadas de condutas e atividades lesivas ao meio ambiente e dá outras providências. Brasília: DOU de 13/2/1998. de espécies exóticas invasoras, incluindo a erradicação e/ou controle, é um problema controverso e complexo. Apesar dos avanços científicos e legais, ainda existe um longo caminho a ser percorrido em direção ao aperfeiçoamento desses componentes. Mas, não podemos perder de foco a urgência no enfrentamento dos problemas relacionados à presença de espécies exóticas invasoras no Brasil.

As informações compiladas reforçam a importância da implementação de medidas de comunicação social e educação ambiental, juntamente com os projetos que objetivam a erradicação de uma dada espécie. Atenção especial deve ser dada ao processo de educação das comunidades locais quanto aos impactos causados por essas espécies, já que uma das finalidades, dentro do manejo de EEI's, deve ser a redução de riscos de introduções, sejam elas intencionais ou não. Os programas de erradicação terão maior chance de sucesso quando houver um apoio consciente dos atores sociais envolvidos no processo.

. Decreto n. 2.519, de 16 de março de 1998. Promulga a Convenção sobre Diversidade Biológica, assinada no Rio de Janeiro, em 5 de junho de 1992.. Brasília: DOU de 17/3/1998.

Decreto $n$. 4.339, de 22 de agosto de 2002. Institui princípios e diretrizes para a implementação da Política Nacional da Biodiversidade. Brasília: DOU de 23/8/2002.

CAVALCANTI, S. M. C. Manejo e controle de danos causados por espécies da fauna. In: CULLEN-JR., L.; RUDRAN, R.; VALLADARES-PADUA, C. (Eds.). Métodos de Estudos em Biologia da Conservação e Manejo da Vida Silvestre. Curitiba: Ed. UFPR; Fundação O Boticário de Proteção à Natureza, 2003.

CONAMA - CONSELHO NACIONAL DO MEIO AMBIENTE. Resolução n. 369, de 28 de março de 2006. Dispõe sobre os casos excepcionais, de utilidade pública, interesse social ou baixo impacto ambiental, que possibilitam a intervenção ou supressão de vegetação em Área de Preservação Permanente - APP. Brasília: DOU de 29/3/2006.

CRAWLEY, M. J.; HARVEY, P. H.; PURVIS, A. Comparative ecology of the native and alien floras of the British Isles. In: SILVERTOWN, J.; FRANCO, M.; HARPER, J. L. (Eds.). Plant life histories: Ecology, philogeny and evolution. Cambridge: Cambridge University Press, 1997. 
CREED, J. C.; OLIVEIRA, A. E. S.; PAULA, A. F. Cnidaria, Scleractinia, Tubastraea coccinea Lesson, 1829 and Tubastraea tagusensis Wells, 1982: Distribution extension. Check List, v. 4, p. 297-300, 2008.

CREED, J. C.; PAULA, A. F. Substratum preference during recruitment of two invasive alien corals onto shallow-subtidal tropical rocky shores. Marine Ecology Progress Series, v. 330, p. 101-111, 2007.

DANSEREAU, P. M. Biogeography: An ecological perspective. New York: The Ronald Press Company, 1957.

DARRIGRAN, G.; DRAGO, I. E. de Invasion of the exotic freshwater mussel Limnoperna fortunei (Dunker, 1857) (Bivalvia: Mytilidae) in South America. Nautilus, v. 114, p. 69, 2000.

DARRIGRAN, G.; PASTORINO, G. Bivalvos invasores en el rio de la Plata, Argentina. Comunicaciones de la Sociedad Malacologica del Uruguay, v. 7, p. 309-311, 1993.

DEBERDT, A. J.; SCHERER, S. B. O javali asselvajado: ocorrência e manejo da espécie no Brasil. Natureza \& Conservação, v. 5, p. 31-44, 2007.

ELTON, C. S. The ecology of invasions by animals and plants. Chicago: The University of Chicago Press, 1958.

FACON, B.; GENTON, B. J.; SHYKOFF, J.; JARNE, P.; ESTOUP, A.; DAVID, P. A general eco-evolutionary framework for understanding bioinvasions. Trends in Ecology \& Evolution, v. 21, p. 130-135, 2005.

GALETTI, M.; SAZIMA, I. Impacto de cães ferais em um fragmento urbano de Floresta Atlântica no sudeste do Brasil. Natureza \& Conservação, v. 4, p. 58-63, 2006.

GNIPPER, R.; JACOBS, A. Espécies exóticas "invasoras": em defesa da vida dos javalis no Paraná - parte II. 2009. Disponível em: <http://www.anda.jor.br/colunaDetalhe.php? idColuna $=200>$. Acesso em: maio 2009.

GODARD, O. O princípio da precaução frente ao dilema da tradução jurídica das demandas sociais: Lições de método decorrentes do caso da vaca louca. In: VARELLA, M. D.; PLATIAU, A. F. B. (Orgs.). Princípio da Precaução. Belo Horizonte: Del Rey, 2004.

GROVES, R. H. Are some weeds sleeping? Some concepts and reasons. Separata de: Euphytica, v. 148, p. 111-120, 2006.

IBAMA - INSTITUTO BRASILEIRO DO MEIO AMBIENTE E DOS RECURSOS NATURAIS RENOVÁVEIS. Instrução Normativa $n$. 141, de 19 de dezembro de 2006. Regulamenta o controle e o manejo ambiental da fauna sinantrópica nociva. Brasília: DOU de 20/12/2006.
IUCN - INTERNATIONAL UNION FOR CONSERVATION OF NATURE. Guias para la prevención de perdidas de diversidad biológica ocasionadas por especies exóticas invasoras. 2000. Disponível em: $<$ http://www.iucn.org/themes/ssc/pubs/ policy/invasivesEng.htm>. Acesso em: fev 2000.

LODGE, D.; SHRADER-FRACHETTE, K. S. Non-indigenous species: ecological explanation, environmental ethics, and public policy. Conservation Biology, v. 17, p. 31-37, 2003.

LOMOLINO, M. V.; RIDDLE, B. R.; BROWN, J. H. Biogeography. 3. ed. Sunderland: Sinauer Associates, Inc., 2006.

MAPA - MINISTÉRIO DAAGRICULTURA, PECUÁRIAE ABASTECIMENTO. Instrução Normativa n. 41, de 2 de julho de 2008. Altera os Anexos I e II da Instrução Normativa n. 52, de 20 de novembro de 2007. DOU de 02/07/2008.

MANSUR, M. C. D.; QUEVEDO, C. B.; SANTOS, C. P.; CALLIL, C. T. Prováveis vias de introdução de Limnoperma fortunei (Dunker, 1857) (Mollusca, Bivalvia, Mytilidae) na bacia da Laguna dos Patos, Rio Grande do Sul e novos registros de invasão no Brasil pelas bacias do Paraná e Paraguai. In: SILVA, J. S. V.; SOUZA, R. C. C. L. (Eds.). Água de Lastro e Bioinvasão. Rio de Janeiro: Interciência, 2004.

MARTINS, C. R.; HAY, J. D. V.; VALLS, J. F. M.; LEITE, L. L.; HENRIQUES, R. P. B. Study on alien gramineous of the Brasilia National Park, Federal District, Brazil. Natureza \& Conservação, v. 5, p. 93-100, 2007.

MATTHEWS, S.; BRAND, K. Sudamérica invadida: el creciente peligro de las especies exóticas invasoras. Nairobi, Kenya: GISP - Global Invasile Species Program, 2005.

MILARÉ, E. Direito do ambiente: a gestão ambiental em foco - doutrina, jurispudência, glossário. 5. ed. São Paulo, SP: Editora Revista dos Tribunais, 2007. 1280 p.

MMA - MINISTÉRIO DO MEIO AMBIENTE DOS RECURSOS HÍDRICOS E DA AMAZÔNIA LEGAL. A Convenção sobre Diversidade Biológica - CDB. Brasília, DF: MMA Ministério do Meio Ambiente, dos Recursos Hídricos e da Amazônia Legal, 2000.

MORSELLO, C. Áreas protegidas públicas e privadas: seleção e manejo. São Paulo: Annablume: FAPESP, 2001.

MS - MINISTÉRIO DA SAÚDE. Vigilância e controle de moluscos de importância epidemiológica: diretrizes técnicas Programa de Vigilância e Controle da Esquistossomose (PCE). Brasília, DF: Editora do Ministério da Saúde, 2007.

NISC - NATIONAL INVASIVE SPECIES COUNCIL. General Guidelines for the Establishment and Evaluation of 
Invasive Species Early Detection and Rapid Response Systems. Washington, DC: Department of the Interior, 2003.

NUÑEZ, M.; QUINTERO, C. ¿Qué hacer con las especies exóticas invasoras? Problemática y técnicas de manejo (algunos ejemplos de especies exóticas en la Patagonia argentina). Bariloche: Cuadernos Universitarios, Centro Regional Universitario Bariloche, Universidad Nacional del Comahue, 2002.

OLIVEIRA, A. E. S.; MACHADO, C. J. S. Quem é quem diante da presença de espécies exóticas no Brasil? Uma leitura do arcabouço institucional-legal voltada para a formulação de uma Política Pública Nacional. In: ENCONTRO NACIONAL DA ASSOSSIAÇÃO NACIONAL DE PÓS-GRADUAÇÃO E PESQUISA EM AMBIENTE E SOCIEDADE, 4. Anais, p. 1-14, jun. 2008. Brasília, DF.

; MEDEIROS, M. S.. What we must do - An exotic invasive species in paradise. Biotemas, v. 21, p. 149-151, 2008.

OLIVEIRA, M. D.; TAKEDA, A. M.; BARROS, L. F.; BARBOSA, D. S.; RESENDE, E. K. Invasion by Limnoperna fortunei (Dunker, 1857) (Bivalvia, Mytilidae) of the Pantanal wetland, Brazil. Biological Invasions, v. 8, p. 97-104, 2006.

ORUETA, J. F. Manual práctico para el manejo de vertebrados invasores en islas de España y Portugal. Barcelona, Espana: Gestión y estudio de espacios naturales, 2003.

PARKES, J. P.; PAULSON, J.; DONLAN, C. J.; CAMPBELL, K. Estudio de factibilidad de erradicar el castor americano (Castor canadensis) en la Patagonia. Buenos Aires, Argentina: Fundación InnovaT, 2008.

PAULA, A. F.; CREED, J. C. Spatial distribution and abundance of non-indigenous coral genus Tubastraea (Cnidaria, Scleractinia) around Ilha Grande, Brazil. Brazilian Journal of Biology, v. 65, p. 661-673, 2005.

PEREIRA, D. G.; OLIVEIRA, M. E. A.; RUIZ-MIRANDA, C. R. Interações entre calitriquídeos exóticos e nativos no Parque Nacional da Serra dos Órgãos - RJ. Espaço \& Geografia, v. 11, p. 67-94, 2008.

PRIMACK, R. B.; RODRIGUES, E. Biologia da conservação. Londrina: Efrain Rodrigues, 2001.

PYSEK, P.; RICHARDSON, D. M.; PERGL, J.; JAROSIK, V.; SIXTOVÁ, Z.; WEBER, E. Geographical and taxonomic biases in invasion ecology. Trends in Ecology \& Evolution, v. 23, p. 237-244, 2008.

REASER, J. K.; GALINDO-LEAL, C.; ZILLER, S. R. Visitas indesejadas: a invasão de espécies exóticas. In: GALINDO-LEAL, C.; CÂMARA, I. G. (Orgs.). Mata Atlântica: biodiversidade, ameaças e perspectivas. São Paulo: Fundação SOS Mata Atlântica; Conservação Internacional, 2005.
RODRIGUEZ, L. F. Can invasive species facilitate native species? Evidence of how, when, and why these impacts occur. Biological Invasions, v. 8, n. 4, p. 927-939, 2006.

SAKAI, A. K.; ALLENDORF, F. W.; HOLT, J. S.; LODGE, D. M.; MOLOFSKY, J.; WITH, K. A.; BAUGHMAN, S.; CABIN, R. J.; COHEN, J. E.; ELLSTRAND, N. C.; MCCAULEY, D. E.; O'NEIL, P.; PARKER, I. M.; THOMPSON, J. N.;WELLER, S. G. The population biology of invasive species. Annual Review of Ecology and Systematics, v. 32, p. 305-332, 2001.

SIMBERLOFF, D. How much information on population biology is needed to manage introduced species? Conservation Biology, v. 17, p. 83-92, 2003.

SIMIÃO, M. S. FISCHER, M. L. Estimativa e inferências do método de controle do molusco exótico Achatina fulica Bowdich, 1822 (Stilommatophora; Achatinidae) em Pontal do Paraná, litoral do Estado do Paraná. Cadernos da Biodiversidade, v. 4, n. 2, p. 74-83, 2004.

SOULÉ, M. E. The onslaught of alien species, and other challenges in the coming decades. Conservation Biology, v. 4, n. 3, p. 233-239, 1990.

ZALBA, S. M. El manejo científico. Un terreno común para la investigación, la gestión de áreas protegidas y el conocimiento local. Revista de la Administración de Parques Nacionales, v. 2, p. 41-43, 2005.

; ZILLER, S. R. Manejo adaptativo de espécies exóticas invasoras: colocando a teoria em prática. Natureza \& Conservação, v. 5, p. 16-22, 2007.

ZAVALETTA, E. S.; HOBBS, R. J. MOONEY, H. A. Viewing invasive species removal in a whole-ecosystem context. Trends in Ecology \& Evolution, v. 16, p. 454-459, 2001.

ZILLER, S. R. A estepe gramíneo-lenhosa no segundo planalto do Paraná: diagnóstico ambiental com enfoque à contaminação biológica. Tese (Doutorado em Engenharia Florestal) - UFPR. Curitiba, 2001.

; ZALBA, S. M. Propostas de ação para prevenção e controle de espécies exóticas invasoras. Natureza \& Conservação, v. 5, p. 8-15, 2007.

; _ _ ZENNI, R. D. Modelo para o desenvolvimento de uma estratégia nacional para espécies exóticas invasoras. Curitiba: The Nature Conservancy; GISP - Global Invasile Species Program, 2007.

Recebido em junho de 2009.

Aceito em dezembro de 2009. Publicado em dezembro de 2010. 